\title{
Effects of exogenous nitric oxide and ethylenediaminetetraacetic acid on cadmium toxicity and accumulation in ryegrass
}

\author{
Q. ZHANG, Y. Y. ZHU, and Y. J. DONG* \\ College of Resources and Environment, Shandong Agricultural University, Tai'an, 271018, P.R. China
}

\begin{abstract}
The effects of exogenous nitric oxide (NO) and ethylenediaminetetraacetic acid (EDTA) on cadmium toxicity and accumulation in ryegrass (Lolium perenne L.) were studied in a hydroponic experiment. The results show that in plants without $\mathrm{Cd}$ application, addition of EDTA and sodium nitroprusside (SNP, an exogenous NO donor) significantly reduced the plant height, root length, and root activity of ryegrass, and significantly increased the $\mathrm{O}_{2}{ }^{-}$generation rate and $\mathrm{H}_{2} \mathrm{O}_{2}$ and malondialdehyde (MDA) content in the aboveground and underground parts of ryegrass. Cadmium stress significantly inhibited ryegrass growth. Addition of SNP or EDTA alleviated Cd toxicity, and addition of both had a better effect. Compared with Cd alone, the shoot height and root length in the Cd+EDTA+SNP treatment increased by 68.8 and $59.6 \%$, and plant fresh and dry masses by 62.6 and $60.0 \%$, respectively. Also, the superoxide dismutase activity in the shoots and roots increased by 32.5 and $67.6 \%$, the peroxidase activity by 49.8 and $67.6 \%$, the ascorbate peroxidase activity by 134 and $102 \%$, the MDA content decreased by 30.4 and $21.8 \%$, and the $\mathrm{O}_{2}{ }^{-}$generation rate by 29.0 and $26.1 \%$, respectively. At the same time, $\mathrm{Cd}$ content in the shoots and roots increased significantly by 89.7 and $30.2 \%$, respectively. Overall, the results suggest that exogenous $\mathrm{NO}$ could enhance Cd tolerance of ryegrass, but addition of EDTA could promote plant $\mathrm{Cd}$ uptake. Combined application of NO and EDTA increased $\mathrm{Cd}$ accumulation in the aboveground parts of ryegrass. In this experiment, the treatment of $100 \mu \mathrm{M} \mathrm{CdCl}_{2}+0.25 \mathrm{mM}$ EDTA $+50 \mu \mathrm{M}$ SNP showed the best effects in promoting $\mathrm{Cd}$ accumulation in ryegrass and enhancing its $\mathrm{Cd}$ tolerance.
\end{abstract}

Additional key words: ascorbate peroxidase, catalase, malondialdehyde, peroxidase, phytoremediation, sodium nitroprusside, superoxide dismutase.

\section{Introduction}

With the development of industry and the rapid expansion of cities, soil heavy metal contamination has become increasingly serious. The cadmium $(\mathrm{Cd})$ is listed as a priority pollutant due to its high content in soil and great threat to human health (Chen et al. 2015, Moynihan et al. 2017). When Cd is absorbed and accumulated by perennial ryegrass, its growth and development could be affected (Bai et al. 2015a).

Phytoremediation is a simple, effective, and environmentally friendly method for soil pollution remediation. However, hyperaccumulators generally have disadvantages of small biomass and long growth cycle (Mahar et al. 2016, Sarwar et al. 2017). Lolium perenne L.is a grass ubiquitous in temperate regions. It has a strong adaptability, high growth rate, high yield, and large absorption capacity for $\mathrm{Cd}$ (Yu et al. 2005, Hu et al. 2013, Bai et al.2015a). By repeatedly pruning and harvesting the ryegrass, soil $\mathrm{Cd}$ content could be gradually decreased. Therefore ryegrass can be used to remediate Cd-contaminated soil (Arienzo et al. 2004, Lou et al. 2013). However, due to the low bioavailability of $\mathrm{Cd}$ and low plant biomass, extraction efficiency is rather low (Mahar et al. 2016, Sarwar et al. 2017). Therefore, various regulatory substances have also been used to stimulate plant growth (Hadi et al. 2010, Sharma et al. 2019).

Nitric oxide (NO) is a gas signaling molecule ubiquitous in plants. It plays a crucial role in plant resistance to stresses (Sahay and Gupta 2017). It has been reported that $\mathrm{NO}$ participates in the regulation of plant response to $\mathrm{Cd}$ stress and alleviates $\mathrm{Cd}$ toxicity to ryegrass by regulating reactive oxygen species (ROS) accumulation and activity of antioxidants (Wang et al. 2013, 2016). Involving $\mathrm{Ca}^{2+}$,

Submitted 6 January 2020, last revision 27 February2020, accepted 11 March 2020.

Abbreviations: APX - ascorbate peroxidase; CAT - catalase; EDTA - ethylenediaminetetraacetic acid; HO- - hydroxyl radical; MDA - malondialdehyde; $\mathrm{O}_{2}{ }^{--}$- superoxide anion radical; POD - peroxidase; ROS - reactive oxygen species; SNP - sodium nitroprusside; SOD - superoxide dismutase.

Acknowledgments: This work was financially supported by the Shandong Provincial Natural Science Foundation of China (ZR2017MD010), the Major Agricultural Application Technology Innovation Project of Shandong Province (SD2019ZZ021), and the National Key Research and Development Support Program of China (2017YFD0201705).

* Corresponding author; e-mail: yuanjiedong@163.com 
cGMP, salicylic acid, and protein kinases, NO signaling can cross-talk with $\mathrm{H}_{2} \mathrm{O}_{2}$ signaling in plants (Crawford and Guo 2005). Sharma et al. (2020) showed that NO can help plants recover from metal toxicity via regulating the antioxidant defense system and cell signaling system.

However, there are studies showing that sodium nitroprusside (SNP, an exogenous NO donor) application inhibited the absorption and transport of $\mathrm{Cd}$ (Dong et al. 2019b). Usman et al. (2009) showed that ethylenediaminetetraacetic acid (EDTA), a synthetic chelating agent, can increase heavy metal availability in soil, accelerate heavy metal transport to the aboveground parts of plants, and improve phytoremediation efficiency. Han et al. (2018) demonstrated that EDTA application increased $\mathrm{Pb}$ and $\mathrm{Cd}$ accumulation in both the aboveground and underground parts of Iris halophila. In addition, Lambrechts et al. (2011) and He et al. (2013) showed that EDTA application improved the accumulation of $\mathrm{Pb}, \mathrm{Cd}$, and $\mathrm{Zn}$ in ryegrass. So far, studies have been conducted on the improvement of phytoremediation efficiency by combined application of plant growth regulators and heavy metal chelators, but few studies have been carried out on combined application of NO and EDTA. Based on the above results, we speculated that adding NO and EDTA could increase $\mathrm{Cd}$ accumulation in ryegrass and alleviate Cd stress at the same time.

Therefore, the objectives of this research were to investigate the effects of exogenous NO and EDTA on the physiological characteristics and $\mathrm{Cd}$ accumulation of ryegrass under $\mathrm{Cd}$ stress and to understand the regulation mechanism of NO and EDTA in ryegrass.

\section{Materials and methods}

The experiment was carried out in the plant nutrition laboratory of the College of Resources and Environment, Shandong Agricultural University, China in March 2018. Ryegrass seeds of uniform size were disinfected with $5 \%$ $(\mathrm{m} / \mathrm{v}) \mathrm{NaClO}$ solution, washed with distilled water, and then sprouted on moist filter paper in the dark at $25^{\circ} \mathrm{C}$ for $3 \mathrm{~d}$. Seedlings were transferred to plastic seed trays filled with matrix and watered with a half-strength Hoagland nutrient solution for one week and full-strength solution for another two weeks.

Uniform seedlings were chosen and transferred into black glass containers (20 seedlings per container). Eight treatments (Table 1 Suppl.) were set up with three replicates. The containers were arranged in a randomized block design. The experiment was implemented in a controlled environment chamber with a 14-h photoperiod, an irradiance of $400 \mu \mathrm{mol} \mathrm{m} \mathrm{m}^{-2} \mathrm{~s}^{-1}$, day/night temperatures of $25 / 18^{\circ} \mathrm{C}$, and a relative humidity of $65 \pm 5 \%$. Nutrient solution was renewed every two days. The ryegrass plants were harvested after two weeks under the treatments.

Plant fresh masses, plant height, root length, and root activity were determined immediately after harvest, and then plants were dried firstly at $105{ }^{\circ} \mathrm{C}$ and then at $70{ }^{\circ} \mathrm{C}$ to constant mass to determine shoot and root dry masses. Root activity was assayed by the triphenyltetrazolium chloride (TTC) method as described by Zhang and Di (2003).

Chlorophyll content was determined according to Knudson et al. (1977). Fresh ryegrass leaves (0.5 g) were extracted with $2 \mathrm{~cm}^{3}$ of $95 \%(\mathrm{v} / \mathrm{v})$ ethanol in the dark, and absorbance of the extract was determined with a spectrophotometer (Shimadzu AA-6300, Kyoto, Japan) at 665,649 , and $470 \mathrm{~nm}$.

Fresh samples $(0.2 \mathrm{~g})$ were ground in $3 \mathrm{~cm}^{3}$ of trichloroacetic acid $(0.1 \%, \mathrm{~m} / \mathrm{v})$. The homogenate was centrifuged at $10000 \mathrm{~g}$ for $10 \mathrm{~min}$ and $1 \mathrm{~cm}^{3}$ of the supernatant was mixed with $4 \mathrm{~cm}^{3}$ of $0.5 \%(\mathrm{~m} / \mathrm{v})$ thiobarbituric acid (TBA). The mixture was heated at $95{ }^{\circ} \mathrm{C}$ for $30 \mathrm{~min}$, chilled on ice, and then centrifuged at $10000 \mathrm{~g}$ for $5 \mathrm{~min}$. The absorbance of the supernatant was measured at $532 \mathrm{~nm}$. Non-specific absorption at $600 \mathrm{~nm}$ was determined and subtracted. The content of malondialdehyde (MDA) was calculated using the coefficient of absorbance of $155 \mathrm{mM}^{-1} \mathrm{~cm}^{-1}$.

For determination of electrolyte leaching, fresh samples $(0.3 \mathrm{~g})$ were put into a $20-\mathrm{cm}^{3}$ test tube with $10 \mathrm{~cm}^{3}$ of deionized water, sealed with clean plastic wrap, let stand at room temperature for $30 \mathrm{~min}$, and the initial conductance (S1) was determined using a Leici DDS-307A (Shanghai, China) conductance meter. After that, the tube was heated in water-bath at $100{ }^{\circ} \mathrm{C}$ for $20 \mathrm{~min}$, cooled, and the final conductance (S2) was determined. Electrolyte leakage [\%] was calculated as $\mathrm{S} 1 / \mathrm{S} 2 \times 100$.

Fresh samples $(1.0 \mathrm{~g})$ were homogenized with $2 \mathrm{~cm}^{3}$ of ice-cold acetone and centrifuged at $10000 \mathrm{~g}$ for 20 min. Titanium reagent $\left(2 \% \mathrm{TiCl}_{2}\right.$ in conc. $\left.\mathrm{HCl}\right)$ was added to a known volume of the supernatant to give a Ti (IV) concentration of $2 \%(\mathrm{~m} / \mathrm{v})$. The $\mathrm{Ti}-\mathrm{H}_{2} \mathrm{O}_{2}$ complex, together with unreacted $\mathrm{Ti}$, was then precipitated by adding $0.2 \mathrm{~cm}^{3}$ of $17 \mathrm{M}$ ammonia solution for each $1 \mathrm{~cm}^{3}$ of the supernatant. The precipitate was washed five times with ice acetone and then dissolved with $1 \mathrm{M} \mathrm{H}_{2} \mathrm{SO}_{4}\left(3 \mathrm{~cm}^{3}\right)$. The absorbance of the solution was measured at $410 \mathrm{~nm}$ against blanks, which had been similarly prepared but without plant tissue (Patterson et al. 1984).

Generation rate of $\mathrm{O}_{2}^{--}$was measured as described by He et al. (2005). Fresh samples $(0.3 \mathrm{~g})$ were ground in liquid $\mathrm{N}_{2}$ and homogenized with $3 \mathrm{~cm}^{3}$ of ice-cold $50 \mathrm{mM}$ sodium phosphate buffer ( $\mathrm{pH} 7.0)$. After centrifugation at $10000 \mathrm{~g}$ for $20 \mathrm{~min}, 1 \mathrm{~cm}^{3}$ of the supernatant was added to a mixture of $0.9 \mathrm{~cm}^{3}$ of $65 \mathrm{mM}$ phosphate buffer solution (pH 7.8) and $0.1 \mathrm{~cm}^{3}$ of $10 \mathrm{mM}$ hydroxyl ammonium chloride and incubated at $25{ }^{\circ} \mathrm{C}$ for $35 \mathrm{~min}$. The reaction mixture $\left(0.5 \mathrm{~cm}^{3}\right)$ was then added to a mixture of $0.5 \mathrm{~cm}^{3}$ of $17 \mathrm{mM}$ sulfanic acid and $0.5 \mathrm{~cm}^{3}$ of $7.8 \mathrm{mM} \alpha$-naphthylamine solution. After $20 \mathrm{~min}$ of reaction, $2 \mathrm{~cm}^{3}$ of ether was added and mixed thoroughly. The solution was then centrifuged at $1200 \mathrm{~g}$ and $4{ }^{\circ} \mathrm{C}$ for $5 \mathrm{~min}$, and absorbance of the supernatant was measured at $530 \mathrm{~nm}$ with a spectrophotometer. Absorbance values were calibrated to a standard curve generated with known concentrations of $\mathrm{HNO}_{2}$.

For extraction of antioxidative enzymes, leaves and roots were homogenized with $50 \mathrm{mM} \mathrm{Na} 2 \mathrm{HPO}_{4}-\mathrm{NaH}_{2} \mathrm{PO}_{4}$ buffer ( $\mathrm{pH} 7.8$ ) containing $0.2 \mathrm{mM}$ EDTA and $2 \%(\mathrm{~m} / \mathrm{v})$ 
insoluble polyvinylpyrrolidone with chilled pestle and mortar. The homogenate was centrifuged at $10000 \mathrm{~g}$ for $20 \mathrm{~min}$ and the supernatant was used for determination of enzyme activities. The whole extraction procedure was carried out at $4{ }^{\circ} \mathrm{C}$.

Superoxide dismutase (SOD) activity was assayed by measuring its ability to inhibit the photochemical reduction of nitroblue tetrazolium following the method of Stewart and Bewley (1980). Catalase (CAT) activity was measured as the decline in absorbance at $240 \mathrm{~nm}$ due to the decrease in $\mathrm{H}_{2} \mathrm{O}_{2}$ concentration according to the method of Patra et al. (1978). Peroxidase (POD) activity was measured as the increase in absorbance at $470 \mathrm{~nm}$ due to guaiacol oxidation (Nickel and Cunningham 1969). Ascorbate peroxidase (APX) activity was measured as the decrease in absorbance at $290 \mathrm{~nm}$ due to the oxidation of ascorbate (Nakano and Asada 1981). The amount of an enzyme that can convert $1 \mu$ mole of substrate in $1 \mathrm{~min}$ is 1 unit (U).

Proline content was measured using the method of Bates et al (1973). Fresh samples (0.2 g) were homogenized in $5 \mathrm{~cm}^{3}$ of $3 \%(\mathrm{~m} / \mathrm{v})$ sulphosalicylic acid solution. After extraction at room temperature, proline concentration was determined at $520 \mathrm{~nm}$ using a standard curve.

Soluble protein content was estimated using the method of Bradford (1976) using bovine serum albumin as a standard.

Dried samples were ground into powder and digested with $\mathrm{HNO}_{3} / \mathrm{HClO}_{4}(3: 1, \mathrm{v} / \mathrm{v})$. Cadmium content was measured by flame atomic absorbance spectrometry (Ali et al. 2002).

Statistical analyses were performed using analysis of variance (ANOVA) of SPSS statistics (v. 19.0). Treatment means were separated using the least significant differences (Duncan test) at the 0.05 probability level.

\section{Results}

Exposure to $\mathrm{Cd}$ significantly inhibited the growth of ryegrass (Table 2 Suppl.). Compared with those in control conditions $(\mathrm{CK})$, the shoot height and root length of ryegrass in the Cd treatment $\left(100 \mu \mathrm{M} \mathrm{CdCl}_{2}\right)$ decreased by 28.34 and $27.46 \%$, respectively, and the fresh and dry masses decreased by 37.21 and $38.05 \%$, respectively. The addition of $100 \mu \mathrm{M}$ sodium nitropruside (SNP) alleviated $\mathrm{Cd}$ stress on ryegrass and the growth inhibition of ryegrass by $\mathrm{Cd}$ was further alleviated by the combined application of $50 \mu \mathrm{M}$ SNP and $250 \mu \mathrm{M}$ EDTA. Compared with those in the $\mathrm{Cd}$ treatment alone, plant height and root length in the $\mathrm{Cd}+\mathrm{EDTA}+\mathrm{SNP}$ treatment increased by 68.83 and $59.61 \%$, respectively, and the fresh and dry masses increased by 62.63 and $60.00 \%$, respectively.

Root activity reflects plant root vitality. Compared with control, the $\mathrm{Cd}$ treatment significantly reduced root activity of ryegrass. Root activity of ryegrass in the $\mathrm{Cd}+\mathrm{SNP}$ and Cd+EDTA treatment was 34.36 and $70.97 \%$, respectively, higher than that in the $\mathrm{Cd}$ treatment and root activity in the Cd+EDTA+SNP treatment was significantly higher (by $106.8 \%$ ) than that in the Cd treatment (Table 2 Suppl.). The results showed that both NO and EDTA could increase the root activity of ryegrass and promote ryegrass growth under Cd stress, and combined application of $\mathrm{NO}$ and EDTA showed better effects.

Cadmium stress significantly decreased the content of photosynthetic pigments in the ryegrass (Table 2 Suppl.). Compared with $\mathrm{CK}$, the content of chlorophylls and carotenoids in the Cd treatment were reduced by 29.09 and $22.73 \%$, respectively. The addition of SNP significantly increased the content of photosynthetic pigments in the ryegrass under $\mathrm{Cd}$ stress. Compared with the $\mathrm{Cd}$ treatment, the $\mathrm{Cd}+\mathrm{EDTA}+\mathrm{SNP}$ treatment increased the contents of chlorophylls and carotenoids by 70.09 and $82.35 \%$, respectively. Therefore, combined application of $\mathrm{NO}$ and EDTA could alleviate $\mathrm{Cd}$ stress and improve $\mathrm{Cd}$ tolerance of ryegrass.

Compared with those in $\mathrm{CK}$, MDA content in ryegrass leaves and roots in the $\mathrm{Cd}$ treatment increased significantly (by 103.5 and $42.52 \%$, respectively) indicating membrane lipid peroxidation in ryegrass under Cd stress (Fig. 1A). The addition of SNP or EDTA reduced MDA accumulation, and the combined application of SNP and EDTA was more effective. Compared with those in the Cd treatment, MDA content in the leaves and roots in the $\mathrm{Cd}+\mathrm{SNP}+\mathrm{EDTA}$ treatment decreased by 30.44 and $21.80 \%$, respectively.

Electrolyte leakage from ryegrass increased significantly under Cd stress (Fig. 1B). Compared with that in $\mathrm{CK}$, the electrolyte leakage in the $\mathrm{Cd}$ treated plants increased by $61.71 \%$. The addition of SNP and/or EDTA reduced electrolyte leakage from ryegrass under Cd stress, and combined application of SNP and EDTA showed better effect. Compared with that in the $\mathrm{Cd}$ treatment, the electrolyte leakage in the $\mathrm{Cd}+\mathrm{SNP}+\mathrm{EDTA}$ treatment decreased by $31.26 \%$.

The $\mathrm{O}_{2}^{--}$generation rate was significantly higher in the $\mathrm{Cd}$ and $\mathrm{Cd}+$ EDTA treatments than in the other treatments, and the $\mathrm{H}_{2} \mathrm{O}_{2}$ content was significantly higher in the $\mathrm{Cd}$ treatment than in the other treatments (Fig. 1C,D). Compared with those in $\mathrm{CK}$, the $\mathrm{O}_{2}{ }^{--}$generation rates in the leaves and roots of ryegrass in the $\mathrm{Cd}$ treatment were increased by 48.07 and $63.95 \%$, respectively, and the $\mathrm{H}_{2} \mathrm{O}_{2}$ content in the leaves and roots was increased by 78.61 and $103.0 \%$, respectively. Exogenous SNP or EDTA decreased the $\mathrm{O}_{2}{ }^{--}$generation rate and $\mathrm{H}_{2} \mathrm{O}_{2}$ content in ryegrass under $\mathrm{Cd}$ stress, and combined application of SNP and EDTA showed better effects. Compared with the $\mathrm{Cd}$ treatment, the $\mathrm{O}_{2}{ }^{-}$generation rates in the leaves and roots in the $\mathrm{Cd}+\mathrm{SNP}+\mathrm{EDTA}$ treatment decreased by 28.99 and $26.11 \%$, respectively, and the $\mathrm{H}_{2} \mathrm{O}_{2}$ content by 42.48 and $40.24 \%$, respectively.

Activity of SOD in ryegrass was significantly decreased under Cd stress (Fig. 2A). Compared with that in CK, SOD activity in the leaves and roots of ryegrass in the $\mathrm{Cd}$ treatment was reduced by 26.46 and $40.34 \%$, respectively. The addition of SNP and/or EDTA helped to recover SOD activity in ryegrass under $\mathrm{Cd}$ stress. Compared with that in the Cd treatment, the SOD activity in the shoots and roots of ryegrass in the $\mathrm{Cd}+\mathrm{SNP}+\mathrm{EDTA}$ treatment was increased by 32.53 and $67.61 \%$, respectively.

The patterns of POD and APX activities were basically similar to that of SOD activity (Fig. $2 B, D$ ). Compared with 
$\mathrm{CK}$, the Cd treatment significantly reduced POD activity in the leaves and roots by 42.27 and $17.03 \%$ and APX activity by 62.90 and $52.63 \%$, respectively. The POD and APX activities were also increased in the Cd+SNP, $\mathrm{Cd}+\mathrm{EDTA}$, and $\mathrm{Cd}+\mathrm{EDTA}+\mathrm{SNP}$ treatments. Compared with that in the $\mathrm{Cd}$ treatment, POD activity in the leaves and roots of ryegrass in the $\mathrm{Cd}+\mathrm{SNP}+\mathrm{EDTA}$ treatment increased by 49.80 and $67.61 \%$ and APX activity increased by 134.1 and $101.6 \%$, respectively. Compared with that in $\mathrm{CK}, \mathrm{CAT}$ activity in ryegrass leaves in the $\mathrm{Cd}$ treatment increased slightly but not significantly (Fig. 2C), while that in the roots decreased by $42.10 \%$. Compared with that in the $\mathrm{Cd}$ treatment, the CAT activity in ryegrass roots in the $\mathrm{Cd}+\mathrm{SNP}+\mathrm{EDTA}$ treatment increased by $45.45 \%$.

Proline accumulation can enhance plant resistance to stress. As shown in Fig. $2 E$, proline content in ryegrass leaves and roots increased significantly in the
$\mathrm{Cd}$ treatment. Compared with that in $\mathrm{CK}$, proline content in ryegrass leaves and roots in the $\mathrm{Cd}$ treatment increased by 74.95 and $115.1 \%$, respectively. Addition of EDTA alone reduced proline content in ryegrass under Cd stress, but addition of SNP alone or in combination with EDTA slightly increased proline content. Compared with that in the Cd treatment, proline content in ryegrass leaves and roots in the $\mathrm{Cd}+\mathrm{SNP}+\mathrm{EDTA}$ treatment increased by 8.52 and $7.43 \%$, respectively.

Soluble protein content decreased significantly in ryegrass under $\mathrm{Cd}$ stress (Fig. $2 F$ ). Compared with $\mathrm{CK}$, the $\mathrm{Cd}$ treatment reduced the soluble protein content of ryegrass leaves and roots by 47.88 and $51.76 \%$, respectively. Addition of SNP or EDTA alone increased soluble protein content, and combined application of SNP and EDTA had better effect. Compared with that in the $\mathrm{Cd}$ treatment, soluble protein content in ryegrass leaves and

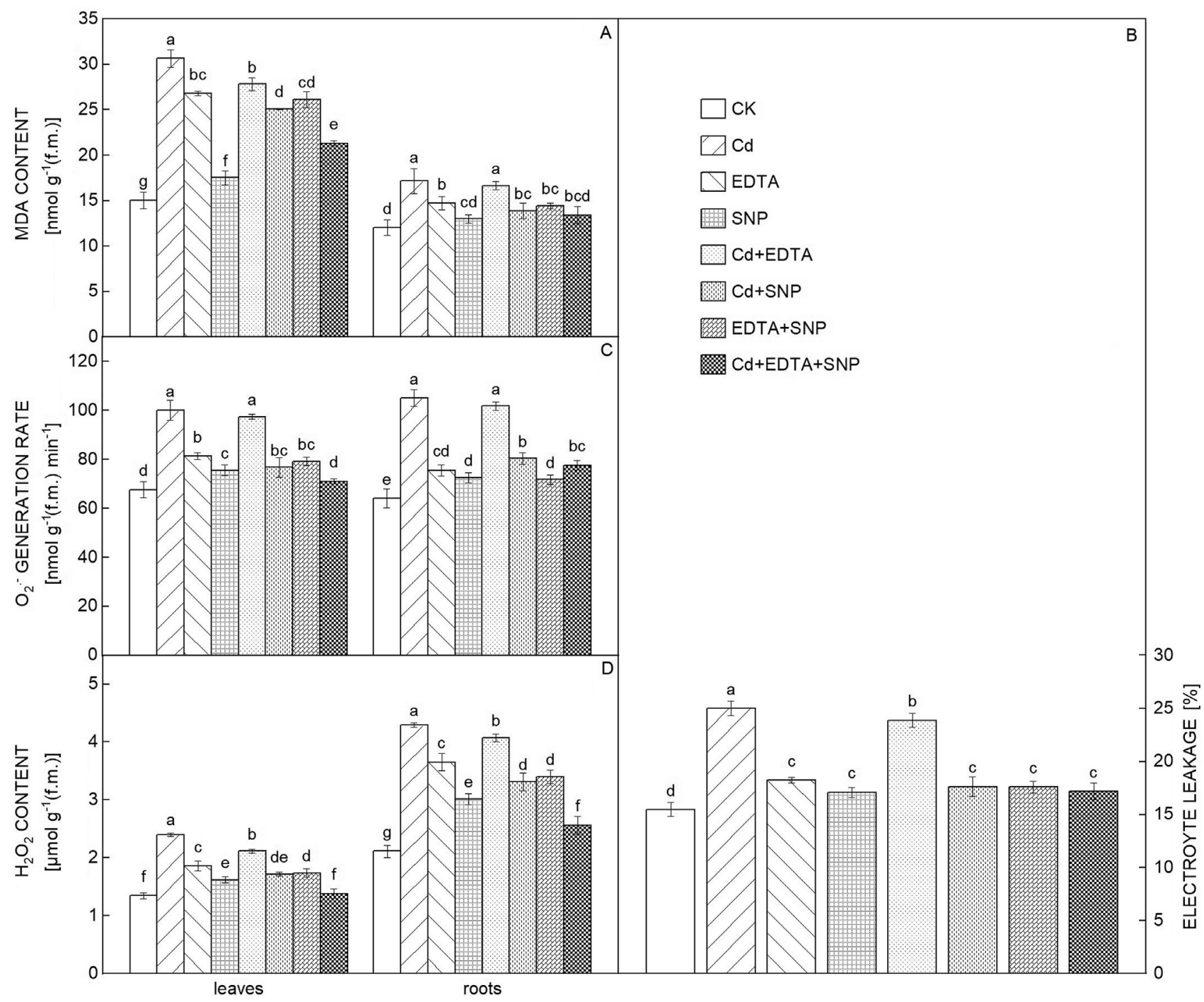

Fig. 1. Malondialdehyde (MDA) content $(A)$, electrolyte leakage $(B), \mathrm{O}_{2}{ }^{-}$generation rate $(C)$, and $\mathrm{H}_{2} \mathrm{O}_{2}$ content $(D)$ in ryegrass under different treatments for two weeks. CK - control grown in Hoagland solution, Cd - Hoagland solution with addition of $100 \mu \mathrm{M} \mathrm{CdCl}_{2}$, EDTA - $0.5 \mathrm{mM}$ EDTA, SNP - $100 \mu \mathrm{M}$ sodium nitroprusside (SNP), Cd+EDTA - $100 \mu \mathrm{M} \mathrm{CdCl}_{2}+0.5 \mathrm{mM}$ EDTA, Cd+SNP - $100 \mu \mathrm{M}$ $\mathrm{CdCl}_{2}+100 \mu \mathrm{M}$ SNP, EDTA+SNP - $0.25 \mathrm{mM}$ EDTA + $50 \mu \mathrm{M} \mathrm{SNP}, \mathrm{Cd}+\mathrm{EDTA}+\mathrm{SNP}-100 \mu \mathrm{M} \mathrm{CdCl}_{2}+0.25 \mathrm{mM}$ EDTA $+50 \mu \mathrm{M}$ SNP. Means \pm SDs, $n=3$; different letters in the same column indicate significant differences between treatments at $P \leq 0.05$. 
roots in the Cd+SNP+EDTA treatment increased by 89.85 and $89.12 \%$, respectively.

Addition of SNP alone increased Cd content in the roots but decreased $\mathrm{Cd}$ content in the leaves of ryegrass treated with $\mathrm{Cd}$ (Fig. 3). Addition of EDTA alone significantly increased $\mathrm{Cd}$ content in both the leaves and roots of ryegrass. Compared with the $\mathrm{Cd}$ treatment, the $\mathrm{Cd}+\mathrm{SNP}+\mathrm{EDTA}$ treatment significantly increased the $\mathrm{Cd}$ content in leaves and roots of Cd-treated ryegrass by 89.67 and $30.16 \%$, respectively, indicating that combined application of SNP and EDTA could significantly improve $\mathrm{Cd}$ absorption and accumulation in ryegrass.

\section{Discussion}

Cadmium stress can decrease root activity and biomass, cause leaf chlorosis, inhibit plant growth, and even cause plant death in severe cases (Luo et al. 2016, Xu et al. 2015). In this study, exposure to $100 \mu \mathrm{mol} \mathrm{CdCl}_{2}$ significantly inhibited the growth of ryegrass (Table 2 Suppl.).
Studies showed that $\mathrm{Cd}$ stress increased the activity of chlorophyllase, an enzyme catalyzing chlorophyll hydrolysis (Kaur et al. 2017), which explains the low chlorophyll content in the $\mathrm{Cd}$ treated plants. When ryegrass was under Cd stress, it seemed that addition of EDTA alone was not able to alleviate $\mathrm{Cd}$ stress but even slightly exacerbated plant grow inhibition. The high concentration $(0.5 \mathrm{mM})$ of EDTA itself might exert a stress on plants. It has been reported that low concentrations of SNP might attenuate $\mathrm{Pb}$ toxicity in ryegrass exposed to $\mathrm{Pb}$ stress (Bai et al. 2015b). Addition of SNP effectively alleviated Cd stress on ryegrass, which is consistent with the results of Wang et al. (2013) that NO effectively alleviated the Cdinduced suppression of ryegrass growth and chlorophyll synthesis and the findings of Zhuo et al. (2017) that NO improved the overall performance of the photo-chemical activities in tall fescue photosystem II under $\mathrm{Cd}^{2+}$ stress. Combined application of SNP and EDTA showed an even better effect than SNP alone with improved root activity and increased photosynthetic pigment content, which might be attributed to the chelating ability of EDTA. Studies have

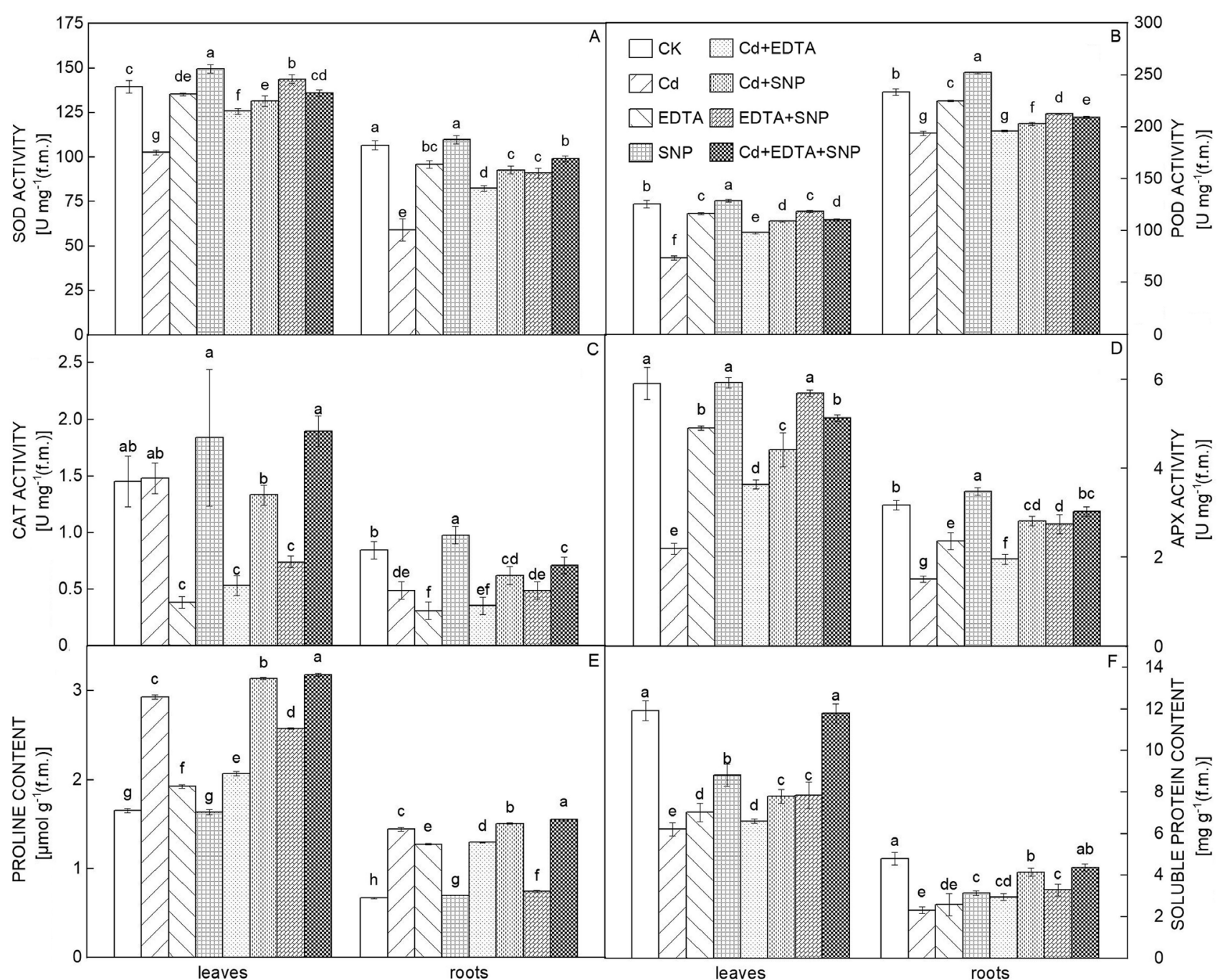

Fig. 2. Superoxide dismutase (SOD, $A$ ), peroxidase (POD, $B$ ), catalase (CAT, $C$ ), and ascorbate peroxidase (APX, $D$ ) activities, proline content $(E)$, and soluble protein content $(F)$ in ryegrass leaves and roots under different treatments (for detail see Fig. 1). SNP - sodium nitroprusside. Means \pm SDs, $n=3$; different letters in the same column indicate significant differences between treatments at $P \leq 0.05$. 
shown that metals enter plants in the form of metal-EDTA complexes when EDTA is applied, which is due to the selective absorption of low-potential complexes by plant roots (Bell et al. 2003). Schaider et al. (2006) showed that Pb-EDTA, Cd-EDTA, and Fe-EDTA complexes are present in the xylem of Brassica juncea. Using high performance liquid chromatography (HPLC), Vassil et al. (1998) demonstrated that $\mathrm{Pb}$ was transported to the shoots of Indian mustard as Pb-EDTA complex. Therefore, in the $\mathrm{Cd}+\mathrm{EDTA}+\mathrm{SNP}$ treatment, that Cd stress on ryegrass might be alleviated partly due to EDTA's complex with $\mathrm{Cd}$, which reduced Cd toxicity to ryegrass.

Malondialdehyde is the terminal product of lipid peroxidation in plants. It is known that Cd toxicity would increase plant cell membrane permeability, and addition of exogenous NO could reduce membrane lipid peroxidation by reducing $\mathrm{O}_{2}{ }^{\cdot-}$ and $\mathrm{H}_{2} \mathrm{O}_{2}$ accumulation (Tan et al. 2008, Sharma et al. 2020). In the Cd treatment, MDA content and electrolyte leakage increased (Fig. 1), indicating that membrane lipid peroxidation occurred, physiological and biochemical functions of ryegrass were impaired, and normal growth of ryegrass was inhibited. However, the addition of SNP alone or the combined application of SNP and EDTA significantly decreased the MDA content and electrolyte leakage in ryegrass under Cd stress. Studies have shown that exogenous NO inhibits the increase in MDA content and electrolyte leakage by reducing lipoxygenase activity (Venkatachalam 2018). Fan et al. (2015) also showed that addition of NO significantly lowered MDA content in bermuda grass, which is consistent with the results of this study. In this study, combined application of SNP and EDTA was more effective in alleviating Cd stress on ryegrass than application of SNP or EDTA alone. The reason might be that EDTA and $\mathrm{Cd}^{2+}$ formed a relatively stable complex. Adhesion of Cd on cell walls was reduced, more $\mathrm{Cd}$ accumulated in mesophyll cell vacuoles and intercellular spaces, and toxic $\mathrm{Cd}$ ions were kept from the protoplasm. Therefore, the combined application of SNP and EDTA could reduce membrane lipid peroxidation caused by Cd stress.

The $\mathrm{O}_{2}^{--}$and $\mathrm{H}_{2} \mathrm{O}_{2}$ accumulate in plants under

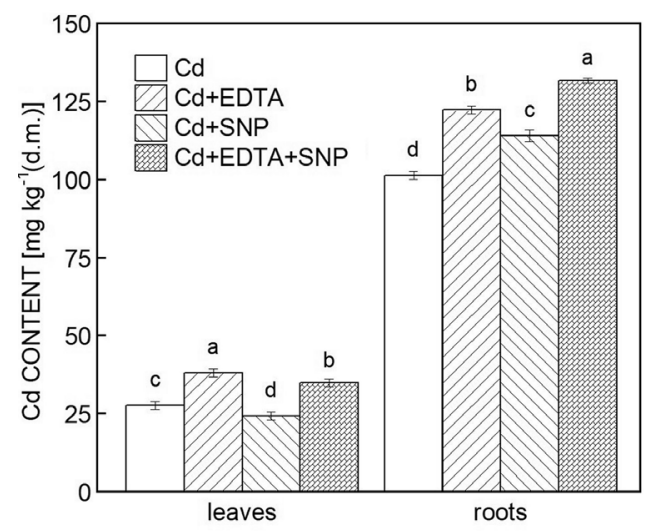

Fig. 3. Cadmium content in ryegrass shoots and roots under $\mathrm{Cd}$ stress alone or together with SNP and EDTA (for detail see Fig. 1). SNP - sodium nitroprusside. Means \pm SDs, $n=3$; different letters in the same column indicate significant differences between treatments at $P \leq 0.05$.
Cd stress, and high Cd content can inhibit the activities of antioxidant enzymes in plants. Accumulation of ROS could inhibit the photosynthesis of plants and damage cell membrane structure (Idrees et al. 2012). In this experiment, $100 \mu \mathrm{M} \mathrm{Cd}$ significantly increased the $\mathrm{O}_{2}{ }^{-}$generation rate and $\mathrm{H}_{2} \mathrm{O}_{2}$ content (Fig. 1) and meanwhile inhibited the SOD, POD, and APX activities in ryegrass (Fig. 2), which was consistent with previous results (Wang et al. 2013). However, this inhibition was alleviated by SNP or/and EDTA addition, and the combined application of SNP and EDTA was most effective. Kapoor et al. (2019) showed that an activated antioxidant system could endow plants with better $\mathrm{Cd}$ tolerance. In this study, the better $\mathrm{Cd}$ tolerance of ryegrass might be explained especially by the increase in CAT activity. In previous experiments we showed that addition of $\mathrm{NO}$ could effectively improve the activities of antioxidant enzymes in peanut under Cd stress (Dong et al. 2019a). Exogenous EDTA could form chelates with $\mathrm{Cd}^{2+}$ to stop it from replacing the metal ions in the catalytic centers of enzymes in plants, thus improving the activities of antioxidant enzymes under $\mathrm{Cd}$ stress. Therefore, addition of SNP or/and EDTA could improve the activities of antioxidant enzymes in ryegrass to remove the excessive ROS and repair damaged cells, and in turn alleviate oxidative stress and improve $\mathrm{Cd}$ tolerance of ryegrass.

Soluble protein and proline are osmotic regulators in plants. Besides, proline can remove ROS, improve antioxidant capacity, and stabilize the structure of biological macromolecules (Filippou et al. 2013). Proline content increased but soluble protein content decreased in ryegrass under $\mathrm{Cd}$ stress (Fig. 2). Combined addition of SNP and EDTA further increased the free proline content and alleviated the inhibitory effect of Cd stress on soluble protein content. Related studies have demonstrated that NO could promote the synthesis and accumulation of proline in plants by increasing $\Delta 1$-pyrrole-5-carboxylic acid synthetase activity and decreasing proline dehydrogenase activity (Su et al. 2018). Therefore, NO and EDTA might improve the osmotic adjustment in ryegrass under $\mathrm{Cd}$ stress.

Cadmium absorbed by plants might be transported through the intercellular spaces via the apoplastic pathway, or through the protoplast channels via the symplastic pathway (White et al. 2002). However, studies found that $\mathrm{Cd}$ stress could accelerate cell maturation and promote the formation of Casparian strip in the roots, thus making it difficult for $\mathrm{Cd}$ to move to the aboveground parts through the extracellular pathway (Krishnamurthy et al. 2009). Qiu et al. (2012) believe that $\mathrm{Cd}$ is mainly transported in plants through the energy-consuming symplastic pathway, and the apoplast pathway only accounts for a small portion. However, the compartmentalization of $\mathrm{Cd}$ in vacuoles in the root cells tends to retain the $\mathrm{Cd}$ in the roots (Lasat et al. 1998), so Cd accumulation in the aboveground parts is generally low. The results showed that $\mathrm{Cd}$ content in ryegrass leaves was significantly increased when EDTA was added alone or in combination with SNP (Fig. 3). As $\mathrm{Cd}$ and Fe share the transporter IRON-REGULATED TRANSPORTER 1, Cd uptake would be stimulated 
when Fe-DEFICIENCY INDUCED TRANSCRIPTION FACTOR, FERRIC REDUCTIONOXIDASE 2, and IRON-REGULATED TRANSPORTER 1 trigger iron starvation effects through NO-mediated upregulation (Sharma et al. 2020). In addition, studies have suggested that EDTA can chelate heavy metals to increase the concentrations of heavy metals in soil solution and reduce the adsorption of $\mathrm{Cd}^{2+}$ on root surface. Therefore, $\mathrm{Cd}$ enters plant roots directly (Luo et al. 2005). Moreover, metal chelates destroy the Casparian strips in the endodermis of plant roots and enter root tissue, which improves their movement to the aboveground parts.

\section{Conclusions}

Combined addition of NO and EDTA alleviated lipid peroxidation and reduction of photosynthetic pigments and improved the osmotic adjustment and antioxidative activity of ryegrass under $\mathrm{Cd}$ stress, thus alleviating the inhibition of ryegrass growth. At the same time, the addition of EDTA promoted $\mathrm{Cd}$ absorption by ryegrass and significantly increased $\mathrm{Cd}$ accumulation in the aboveground parts. Of all the treatments used in this experiment, the $\mathrm{Cd}+\mathrm{EDTA}+\mathrm{SNP}$ treatment was the most effective not only in improving $\mathrm{Cd}$ accumulation in ryegrass, but also in enhancing $\mathrm{Cd}$ resistance of ryegrass.

\section{References}

Ali, N.A., Bernal, M.P., Ater, M.: Tolerance and bioaccumulation of copper in Phragmites australis and Zea mays. - Plant Soil 239: 103-111, 2002.

Arienzo, M., Adamo, P., Cozzolino, V.: The potential of Lolium perenne for revegetation of contaminated soil from a metallurgical site. - Sci. total Environ. 319: 13-25, 2004.

Bai, X.Y., Dong, Y.J., Kong, J., Xu, L.L., Liu S.: Effects of application of salicylic acid alleviates cadmium toxicity in perennial ryegrass. - Plant Growth Regul. 75: 695-706, 2015a.

Bai, X.Y., Dong,Y.J., Wang, Q.H., Xu, L.L., Kong, J., Liu, S.: Effects of lead and nitric oxide on photosynthesis, antioxidative ability, and mineral element content of perennial ryegrass. - Biol. Plant. 59: 163-170, 2015 b.

Bates, L.S., Waldern, S.P., Teare, I.D.: Rapid determination of free proline for water-stress studies. - Plant Soil 39: 205-207, 1973.

Bell, P.F., McLaughlin, M.J., Cozens, G., Stevens, D.P., Owens, G., South, H.: Plant uptake of ${ }^{14} \mathrm{C}$-EDTA, ${ }^{14} \mathrm{C}$-citrate, and ${ }^{14} \mathrm{C}$-histidine from chelator-buffered and conventional hydroponic solutions. - Plant Soil 253: 311-319, 2003.

Bradford, M.M.: A rapid and sensitive method for the quantitation of microgram quantities of protein utilizing the principle of protein dyes binding. - Anal. Biochem. 72: 248-254, 1976.

Chen, H.Y., Teng, Y.G., Lu, S.J., Wang, Y.Y., Wang, J.S.: Contamination features and health risk of soil heavy metals in China. - Sci. total Environ. 512-513:143-153, 2015.

Crawford, N.M., Guo, F.: New insights into nitric oxide metabolism and regulatory functions. - Trends Plant Sci. 10: 195-200, 2005.

Dong, Y.J., Chen, W.F., Bai, X.Y., Liu, F.Z., Wan, Y.S.: Effects of exogenous nitric oxide and 24-epibrassinolide on physiological characteristics of peanut under cadmium stress.
- Pedosphere 29: 45-59, 2019a.

Dong, Y.J., Chen, W.F., Liu, F.Z., Wan. Y.S.: Physiological responses of peanut seedlings to exposure to low or high cadmium concentration and the alleviating effect of exogenous nitric oxide to high cadmium concentration stress. - Plant Biosystems 154: 941-953, $2019 \mathrm{~b}$.

Fan, J., Chen, K., Amombo, E., Hu, Z.R., Chen, L., Fu, J.M.: Physiological and molecular mechanism of nitric oxide (NO) involved in bermudagrass response to cold stress. - PLoS ONE 10: 1-14, 2015.

Filippou, P., Antoniou, C., Fotopoulos, V.: The nitric oxide donor sodium nitroprusside regulates polyamine and proline metabolism in leaves of Medicago truncatula plants. - Free Radicals Biol. Med. 56: 172-183, 2013.

Hadi, F., Bano, A., Fuller, M.P.: The improved phytoextraction of lead $(\mathrm{Pb})$ and the growth of maize (Zea mays L.): the role of plant growth regulators $\left(\mathrm{GA}_{3}\right.$ and IAA) and EDTA alone and in combinations. - Chemosphere 80: 457-462, 2010.

Han, Y.L., Zhang, L.L., Gu, J.G., Zhao, J.Z., Fu, J.J.: Citric acid and EDTA on the growth, photosynthetic properties and heavy metal accumulation of Iris halophila Pall. cultivated in $\mathrm{Pb}$ mine tailings. - Int. Biodeterioration Biodegrad. 128: 15-21, 2018

He, S.Y., Wu, Q.L., He, Z.L.: Effect of DA-6 and EDTA alone or in combination on uptake, subcellular distribution and chemical form of $\mathrm{Pb}$ in Lolium perenne. - Chemosphere 93: 2782-2788, 2013.

He, Y., Liu, Y., Cao, W., Hua, M., Xu, B., Huang, B.: Effects of salicylic acid on heat tolerance associated with antioxidant metabolism in Kentucky bluegrass. - Crop Sci. 45: 988-995, 2005.

Hu, J.L., Wu, S.C., Wu, F.Y., Leung, H.M., Lin, X.G., Wong, M.H.: Arbuscular mycorrhizal fungi enhance both absorption and stabilization of $\mathrm{Cd}$ by Alfred stonecrop (Sedum alfredii Hance) and perennial ryegrass (Lolium perenne L.) in a Cdcontaminated acidic soil. - Chemosphere. 93: 1359-1365, 2013.

Idrees, M., Naeem, M., Khan, M.N., Aftab, T., Khan, M.M.A., Moinuddin: Alleviation of salt stress in lemongrass by salicylic acid. - Protoplasma 249: 709-720, 2012.

Kapoor, D., Singh, M.P., Kaur, S., Bhardwaj, R., Zheng, B.S., Sharma, A.: Modulation of the functional components of growth, photosynthesis, and anti-oxidant stress markers in cadmium exposed Brassica juncea L. - Plants 8: 260, 2019.

Kaur, R., Yadav, P., Sharma, A., Thukral, A.K., Kumar, V., Kohli, S.K., Bhardwaj, R.: Castasterone and citric acid treatment restores photosynthetic attributes in Brassica juncea L. under Cd(II) toxicity. - Ecotoxicol. environ. Safety 145: 466-475, 2017.

Knudson, L.L., Tibbitts, T.W., Edwards, G.E.: Measurement of ozone injury by determination of leaf chlorophyll concentration. - Plant Physiol. 60: 606-608, 1977.

Krishnamurthy, P., Ranathunge, K., Franke, R., Prakash, H.S., Schreiber, L., Mathew, M.K.: The role of root apoplastic transport barriers in salt tolerance of rice (Oryza sativa L.). Planta 230: 119-134, 2009.

Lambrechts, T., Gustot, Q., Couder, E., Houben, D., Iserentant, A., Lutts, S.: Comparison of EDTA-enhanced phytoextraction and phytostabilisation strategies with Lolium perenne on a heavy metal contaminated soil. Chemosphere 85: 1290-1298, 2011.

Lasat, M.M., Baker, A.J.M., Kochian, L.V.: Altered Zn compartmentation in the root symplasm and stimulated $\mathrm{Zn}$ absorption into the leaf as mechanisms involved in $\mathrm{Zn}$ hyperaccumulation in Thlaspi caerulescens. - Plant Physiol. 118: 875-883, 1998. 
Lou, Y.H., Luo, H.J., Hu, T., Li, H.Y., Fu, J.M.: Toxic effects, uptake, and translocation of $\mathrm{Cd}$ and $\mathrm{Pb}$ in perennial ryegrass. - Ecotoxicology 22: 207-214, 2013.

Luo, C.L., Shen, Z.G., Li, X.D.: Enhanced phytoextraction of $\mathrm{Cu}, \mathrm{Pb}, \mathrm{Zn}$ and $\mathrm{Cd}$ with EDTA and EDDS. - Chemosphere 59: 1-11, 2005.

Luo, J., Qi, S.H., Gu, X.W.S., Hou, T., Lin, L.H.: Ecological risk assessment of EDTA-assisted phytoremediation of $\mathrm{Cd}$ under different cultivation systems. - Bull. Environ. Contam. Toxicol. 96: 259-264, 2016.

Mahar, A., Wang, P., Ali, A., Awasthi, M.K., Lahori, A.H., Wang, Q., Li, R.H., Zhang, Z.Q.: Challenges and opportunities in the phytoremediation of heavy metals contaminated soils: a review. - Ecotoxicol. environ. Safety 126: 111-121, 2016.

Moynihan, M., Peterson, K.E., Cantoral, A., Song, P.X.K., Jones, A., Solano-González, M., Meeker, J.D., Basu, N., TéllezRojo, M.M.: Dietary predictors of urinary cadmium among pregnant women and children. - Sci. total Environ. 575: 12551262, 2017.

Nakano, Y., Asada, K.: Hydrogen peroxide is scavenged by ascorbate-specific peroxidase in spinach chloroplasts. - Plant Cell Physiol. 22: 867-880, 1981.

Nickel, K.S., Cunningham, B.A.: Improved peroxidase assay method using leuco-2,3,6-trichlcroindophenol and application to comparative measurements of peroxidase catalysis. - Anal. Biochem. 27: 292-299, 1969.

Patra, H.L., Kar, M., Mishre, D.: Catalase activity in leaves and cotyledons during plant development and senescence. Biochem Pharmacol. 172: 385-390, 1978.

Patterson, B.D., MacRae, E.A., Ferguson, I.B.: Estimation of hydrogen peroxide in plant extracts using titanium (IV). Anal. Biochem. 139: 487-492, 1984.

Qiu, R.L., Tang, Y.T., Zeng, X.W., Thangavel, P., Tang, L., Gan, Y.Y., Ying, R.R., Wang, S.Z.: Mechanisms of $\mathrm{Cd}$ hyperaccumulation and detoxification in heavy metal hyperaccumulators: how plants cope with Cd. - Progr. Bot. 73: 127-159, 2012.

Sahay, S., Gupta, M.: An update on nitric oxide and its benign role in plant responses under metal stress. - Nitric Oxide 67: $39-52,2017$.

Sarwar, N., Imran, M., Shaheen, M.R., Ishaque, W., Kamran, M.A., Matloob, A., Rehim, A., Hussain, S.: Phytoremediation strategies for soils contaminated with heavy metals: modifications and future perspectives. - Chemosphere 171: 710-721, 2017.

Schaider, L.A., Parker, D.R., Sedlak, D.L.: Uptake of EDTAcomplexed $\mathrm{Pb}, \mathrm{Cd}$ and $\mathrm{Fe}$ by solution and sand-cultured Brassica juncea. - Plant Soil. 286: 377-391, 2006.

Sharma, A., Shahzad, B., Kumar, V., Kohli, S.K., Sidhu, G.P.S., Bali, A.S., Handa, N., Kapoor, D., Bhardwaj, R., Zheng, B.S.: Phytohormones regulate accumulation of osmolytes under abiotic stress. - Biomolecules 9: 285, 2019.

Sharma, A., Soares, C., Sousa, B., Martins, M., Kumar, V., Shahzad, B., Sidhu, G.P.S., Bali, A.S., Asgher, M., Bhardwaj,
R., Thukral, A.K., Fidalgo, F., Zheng, B.S.: Nitric oxidemediated regulation of oxidative stress in plants under metal stress: a review on molecular and biochemical aspects. Physiol. Plant. 168: 318-344, 2020.

Stewart, R.C., Bewley, J.D.: Lipid peroxidation associated with accelerated aging of soybean axes. - Plant Physiol. 65: 245$248,1980$.

Su, J.C., Zhang, Y.H., Nie, Y., Cheng, D., Wang, R., Hu, H.L., Chen, J., Zhang, J.F., Du, Y.W., Shen, W.B.: Hydrogeninduced osmotic tolerance is associated with nitric oxidemediated proline accumulation and reestablishment of redox balance in alfalfa seedlings. - Environ. exp. Bot. 147: 249260,2018

Tan, J.F., Zhao, H.J., Hong, J.P., Han, Y.L., Li, H., Zhao, W.C.: Effects of exogenous nitric oxide on photosynthesis, antioxidant capacity and proline accumulation in wheat seedlings subjected to osmotic stress. - World J. agr. Sci. 4: 307-313, 2008.

Usman, A.R.A., Mohamed, H.M.: Effect of microbial inoculation and EDTA on the uptake and translocation of heavy metal by corn and sunflower. - Chemosphere 76: 893-899, 2009.

Vassil, A.D., Kapulnik, Y., Raskin, I., Salt, D.E.: The role of EDTA in lead transport and accumulation by Indian mustard. - Plant Physiol. 117: 447-453, 1998.

Venkatachalam, K.: Exogenous nitric oxide treatment impacts antioxidant response and alleviates chilling injuries in longkong pericarp. - Scientia Hort. 237: 311-317, 2018.

Wang, Q.H., Liang, X., Dong, Y.J., Xu, L.L., Zhang, X.W., Hou, J., Fan, Z.Y.: Effects of exogenous nitric oxide on cadmium toxicity, element contents and antioxidative system in perennial ryegrass. - Plant Growth Regul. 69: 11-20, 2013.

Wang, W.W., Bai, X.Y., Dong, Y.J., Chen, W.F., Song, Y.L., Tian, X.Y.: Effects of application of exogenous NO on the physiological characteristics of perennial ryegrass grown in Cd contaminated soil. - J. Soil Sci. Plant Nutr. 16: 731-744, 2016.

White, P.J., Whiting, S.N., Baker, A.J., Broadley, M.R.: Does zinc move apoplastically to the xylem in roots of Thlaspi caerulescens? - New Phytol. 153: 201-207, 2002.

Xu, L.L., Fan, Z.Y., Dong, Y.J., Kong, J., Bai, X.Y.: Effects of exogenous salicylic acid and nitric oxide on physiological characteristics of two peanut cultivars under cadmium stress. - Biol. Plant. 59: 171-182, 2015.

Yu, X.Z., Cheng, J.M., Wong, M.H.: Earthworm-mycorrhiza interaction on Cd uptake and growth of ryegrass. - Soil Biol. Biochem. 37: 195-201, 2005.

Zhang, Z.L., Di, W.J. (ed.): Laboratory Guide for Plant Physiology. - Higher Education Press, Beijing 2003.

Zhuo, Y.Q., Qiu, S., Amombo, E., Zhu, Q., Tang, D.Y., Huang, M.Y., Han, X.L., Chen, L., Wang, S., Chen, K., Sun, J.: Nitric oxide alleviates cadmium toxicity in tall fescue photosystem II on the electron donor side. - Environ. Exp. Bot. 137: 110$118,2017$. 